\title{
From genotype to EEG endophenotype: a route for post-genomic understanding of complex psychiatric disease?
}

\author{
Eco JC de Geus',2,3
}

\begin{abstract}
Twin and family studies have shown the importance of biological variation in psychiatric disorders. Heritability estimates vary from $50 \%$ to $80 \%$ for cognitive disorders, such as schizophrenia, attention deficit hyperactivity disorder and autism, and from $40 \%$ to $65 \%$ for affective disorders, such as major depression, anxiety disorders and substance abuse. Pinpointing the actual genetic variants responsible for this heritability has proven difficult, even in the recent wave of genome-wide association studies. Brain endophenotypes derived from electroencephalography (EEG) have been proposed as a way to support gene-finding efforts. A variety of EEG and event-related-potential endophenotypes are linked to psychiatric disorders, and twin studies have shown a striking genetic contribution to these endophenotypes. However, the clear need for very large sample sizes strongly limits the usefulness of EEG endophenotypes in gene-finding studies. They require extended laboratory recordings with sophisticated and expensive equipment that are not amenable to epidemiology-scaled samples. Instead, EEG endophenotypes are far more promising as tools to make sense of candidate genetic variants that derive from association studies; existing clinical data from patients or questionnaire-based assessment of psychiatric symptoms in the population at large are better suited for the association studies themselves. EEG endophenotypes can help us understand where in the brain, in which stage and during what type of information processing these genetic variants have a role. Such testing can be done in the more modest samples that are feasible for EEG research. With increased understanding of how genes affect the brain, combinations of genetic risk scores and brain endophenotypes may become part of the future classification of psychiatric disorders.
\end{abstract}

\section{The importance of genetic factors in psychiatric disorders}

Mental illness continues to incur negative attitudes, often characterized by fear, stigma and rejection, but the idea that it reflects a 'weakness of character' that can be overcome by sheer willpower is increasingly losing ground [1]. Most people now understand that psychiatric disorders are caused by a sick organ, just like heart disease, although in this case the organ happens to be the most complex organ we possess, the brain.

Appreciation of the importance of biological factors in psychiatric disorders has been strongly reinforced by

\footnotetext{
*Correspondence: eco@psy.vu.nl

'Department of Biological Psychology, VU University, van der Boechorststraat 1,

1081 BT, Amsterdam, the Netherlands

Full list of author information is available at the end of the article
}

evidence from twin and family studies that genetic variation between individuals has a key role in the risk for these disorders. Heritability estimates for cognitive disorders, such as schizophrenia, attention deficit hyperactivity disorder (ADHD) and autism, range from $50 \%$ to $80 \%$ [2-6]. For affective disorders, such as major depression, anxiety disorders and substance abuse, estimates range from $40 \%$ to $65 \%[3,7,8]$. However, pinpointing the actual genetic variants responsible for this heritability has proven difficult. The most successful gene-finding approach, genome-wide association (GWA), has uncovered many genetic variants for conditions such as diabetes [9], Crohn's disease [10] and atherosclerotic risk $[11,12]$, but this method has, as yet, not been as successful for psychiatric disorders [13]. For schizophrenia and autism only a handful of genetic variants have been identified [14-16], and there are currently no confirmed genetic variants associated with ADHD and depression. 


\section{Can endophenotypes help us to find genetic variants that influence psychiatric disease?}

The difficulty in identifying actual genetic variants probably relates to the complexity of psychiatric phenotypes, which in turn reflects the complexity of the brain processes that underlie them. To reduce this complexity it has been proposed to focus genetic studies on so-called brain endophenotypes [2,17-19]. The basic reasoning is that it may be easier to detect the effect of a genetic variant on a more elementary neurobiological trait because there may be fewer genetic variants with larger effect sizes involved in these traits. An important source of brain endophenotypes is electroencephalography (EEG). An EEG signal is recorded non-invasively from electrodes placed on the scalp and depicts the ongoing electrical activity of the brain. An event-related potential (ERP) is the brain's electrical response to the occurrence of a specific event. The event is usually a stimulus - a word or picture presented on a display - but it can also be generated internally, for instance by the intention to move a limb. An example of an ERP is the P3, a positive wave that occurs about $300 \mathrm{~ms}$ after a motivationally significant stimulus. The P3 reflects the activity of the locus-coeruleus-norepinephrine system [20], which facilitates the behavioral and cognitive responses to motivationally significant events, and it may be the central nervous system component of the fight-flight response [21].

Can EEG and ERP endophenotypes help identify and confirm novel genetic risk factors for psychiatric disease? To do so they must, first of all, be predictive of psychiatric disorders. There is a huge corpus of literature on the use of EEG or ERP endophenotypes as risk markers for psychiatric disorder. It is impossible to review this corpus in a few words here, but two examples may serve to illustrate it. First, frontal asymmetry of EEG $\alpha$ power (FA) has been studied extensively as a correlate of individual differences in emotional response. Greater left hemispheric activity has been associated with a tendency to approach things of interest, and greater right hemispheric activity with withdrawal-related tendencies $[22,23]$. Disturbances in the emotional dimension of approach versus withdrawal have a key role in the liability to develop psychopathology such as depression and anxiety disorders $[24,25]$, with which the FA has indeed been found to be associated $[2,26,27]$. Second, reduced amplitude of the P3 is found in a variety of psychiatric and behavioral disorders, but most notably schizophrenia [28] and alcohol abuse [29]. The reduction in P3 amplitude reflects a genetic predisposition for these disorders rather than a mere functional consequence, because it does not normalize after successful treatment [28] and is also found in unaffected relatives [29]. The latter point is important. To tag a relevant part of the
Table 1. Heritability estimates for EEG/ERP traits*

\begin{tabular}{lcc}
\hline EEG/ERP trait & $\begin{array}{c}\text { Heritability } \\
\text { estimates }\end{array}$ & References \\
\hline Power a band & $86-96 \%$ & {$[30-32]$} \\
Power $\theta$ band & $80-90 \%$ & {$[30,32]$} \\
Power $\beta$ band & $70-82 \%$ & {$[30,32]$} \\
Peak frequency a band & $71-83 \%$ & {$[33,34]$} \\
Path length a band & $48-68 \%$ & {$[31]$} \\
Cluster coefficient $\beta$ band & $25-40 \%$ & {$[31]$} \\
Path length $\beta$ band & $29-42 \%$ & {$[31]$} \\
Cluster coefficient a band & $37-45 \%$ & {$[31]$} \\
Long range temporal correlations a band & $47 \%$ & {$[35]$} \\
Long range temporal correlations $\beta$ band & $42 \%$ & {$[35]$} \\
Frontal EEG asymmetry a band & $1-37 \%$ & {$[36]$} \\
P50 amplitude attenuation & $34 \%$ & {$[47]$} \\
N1 amplitude attenuation & $45 \%$ & {$[47]$} \\
P2 amplitude attenuation & $54 \%$ & {$[47]$} \\
Mismatch negativity & $58 \%$ & {$[37]$} \\
Posterior N1 amplitude & $50 \%$ & {$[38]$} \\
Posterior N1 latency & $45 \%$ & {$[38]$} \\
Anterior N1 amplitude & $22 \%$ & {$[38]$} \\
Anterior N1 latency & $43 \%$ & {$[38]$} \\
Go/Nogo difference N2 amplitude & $53 \%$ & {$[39]$} \\
Error positivity & $52 \%$ & {$[40]$} \\
Error-related negativity & $47 \%$ & {$[40]$} \\
P3 amplitude & $50-80 \%$ & {$[37,41,42]$} \\
P3 latency & $38-50 \%$ & {$[37,41,42]$} \\
Onset lateralized readiness potential & $54-62 \%$ & {$[43]$} \\
Peak lateralized readiness potential latency & $38-45 \%$ & {$[43]$} \\
\hline Data ar from studes comparng & -13 \\
\hline
\end{tabular}

*Data are from studies comparing the resemblance in monozygotic twins with that in dizygotic twins. If a measure was available at multiple electrodes, the electrodes with highest amplitude were selected. A range of heritabilities reflects either the variation in estimates across multiple studies or across multiple age groups within a single study.

pathway from genetic variation to psychiatric disorder, the endophenotypes must be heritable traits and their heritability must arise partly from the genetic variants that also influence the psychiatric disorder [17].

In the Netherlands Twin Register, we have estimated the heritability of a variety of EEG and ERP endophenotypes, and similar work has been undertaken by colleagues from twin registries around the world [30-43]; Table 1 illustrates the findings from these studies. A striking genetic contribution is found to almost all EEG and ERP traits. Resting EEG power is even among the most heritable traits in humans. This high heritability does not simply reflect 'trivial' heritable similarities in the composition of the skull or other tissue layers between electrode and brain. Almost identical heritability 
estimates are obtained when power is computed in signals from magnetoencephalography, which are almost undistorted by tissues covering the brain $[44,45]$.

To return to the question of whether these heritable EEG and ERP endophenotypes can help to identify and confirm novel genetic risk factors for psychiatric disorders: GWA has been the most successful method for detecting novel potential genetic variants for complex traits. However, it has a limited ability to detect common variants with very small effect sizes and also rare variants with very low allele frequencies. Both limitations can be tackled by increasing the size of the (pooled) samples, although the second also needs increased depth of coverage of genomic variation, perhaps even by full sequencing. Unfortunately, the clear need for very large sample sizes in GWA studies strongly limits the usefulness of EEG/ERP measurements in the gene discovery phase. EEG/ERP measurements require controlled laboratory experiments with sophisticated and rather expensive equipment. They take up to at least 20 to 30 minutes and this may increase up to hours if error measurement is to be contained using the more complex derived measures [31]. Measuring EEG/ERP, in short, is too hard to do on the tens of thousands of subjects needed in a GWA, particularly when contrasted with the use of existing patient records or questionnaire-based assessment of psychiatric symptoms.

\section{Endophenotypes can help us make sense of genetic variants influencing psychiatric disorders}

The real value of brain endophenotypes may come after gene finding, when they help us confirm the biological meaning of the genetic variants that were detected using GWA on psychiatric symptoms and diagnoses. One of the lessons of successful GWA studies in other fields is that they point us to genetic pathways that were not previously known to be involved in the trait. Finding genetic variants for psychiatric symptoms and diagnoses needs, therefore, to be followed up by an understanding of what these 'psychiatric' genes do in the brain. Testing the association of the risk alleles with EEG and ERP endophenotypes can help us understand where in the brain, in which stage, and during what type of information processing the genetic variant has a role. Such testing can be done in more modest samples, which are more feasible for EEG research.

Could EEG and ERP endophenotypes be more widely applied, apart from helping us to understand how genetic variants cause psychiatric risk? The main system for classifying psychiatric disorders is the Diagnostic and Statistical Manual of Mental Disorders (DSM-V). This system is based on a tally of symptoms and their impact on daily functioning reported by patients or their caregivers. The DSM currently is undergoing substantial revision [46], and a question that repeatedly surfaces is whether we can use the combination of genetic risk scores and brain endophenotypes to better classify psychiatric disorders. Progress in research on the genetics of brain endophenotypes may be key to the successful development of such a classification system. This system would base our diagnostic procedures more solidly on biology and reinforce the notion that psychiatric disorders are disorders of the brain.

\section{Abbreviations}

ADHD, attention deficit hyperactivity disorder; DSM, Diagnostic and Statistical Manual; EEG, electroencephalography; ERP event related potential; GWA, genome-wide association.

\section{Competing interests}

The author declares that he has no competing interests.

\section{Author details}

'Department of Biological Psychology, VU University, van der Boechorststraat 1, 1081 BT, Amsterdam, the Netherlands. ${ }^{2}$ Neuroscience Campus Amsterdam, VU University Medical Center, De Boelelaan 1085, 1081 HV, Amsterdam, the Netherlands. ${ }^{3} \mathrm{EMGO}+$ Institute for Health and Care Research, VU University Medical Center, De Boelelaan 1117, 1081 HV, Amsterdam, the Netherlands.

Published: 7 September 2010

\section{References}

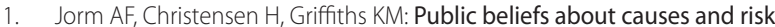
factors for mental disorders: changes in Australia over 8 years. Soc Psychiatry Psychiatr Epidemiol 2005, 40:764-767.

2. Gottesman II, Gould TD: The endophenotype concept in psychiatry: etymology and strategic intentions. Am J Psychiatry 2003, 160:636-645.

3. Hettema JM, Neale MC, Kendler KS: A review and meta-analysis of the genetic epidemiology of anxiety disorders. Am J Psychiatry 2001, 158:1568-1578.

4. Rhee SH, Hewitt JK, Young SE, Corley RP, Crowley TJ, Stallings MC: Genetic and environmental influences on substance initiation, use, and problem use in adolescents. Arch Gen Psychiatry 2003, 60:1256-1264.

5. Rutter M: Genetic studies of autism: from the 1970 s into the millennium. J Abnorm Child Psychol 2000, 28:3-14.

6. Rietveld MJ, Hudziak JJ, Bartels M, Van Beijsterveldt CE, Boomsma Dl: Heritability of attention problems in children: longitudinal results from a study of twins, age 3 to 12. J Child Psychol Psychiatry 2004, 45:577-588.

7. Sullivan PF, Neale MC, Kendler KS: Genetic epidemiology of major depression: Review and meta-analysis. Am J Psychiatry 2000, 157:1552-1562.

8. Agrawal A, Lynskey MT: The genetic epidemiology of cannabis use, abuse and dependence. Addiction 2006, 101:801-812.

9. McCarthy MI, Zeggini E: Genome-wide association studies in type 2 diabetes. Curr Diab Rep 2009, 9:164-171.

10. Barrett JC, Hansoul S, Nicolae DL, Cho JH, Duerr RH, Rioux JD, Brant SR, Silverberg MS, Taylor KD, Barmada MM, Bitton A, Dassopoulos T, Datta LW, Green T, Griffiths AM, Kistner EO, Murtha MT, Regueiro MD, Rotter Jl, Schumm LP, Steinhart AH, Targan SR, Xavier RJ, Libioulle C, Sandor C, Lathrop M, Belaiche J, Dewit O, Gut I, Heath S, et al.: Genome-wide association defines more than 30 distinct susceptibility loci for Crohn's disease. Nat Genet 2008, 40:955-962.

11. Lotta LA: Genome-wide association studies in atherothrombosis. Eur J Intern Med 2010, 21:74-78.

12. Aulchenko YS, Ripatti S, Lindqvist I, Boomsma D, Heid IM, Pramstaller PP, Penninx BWJH, Janssens ACJW, Wilson JF, Spector T, Martin NG, Pedersen NL, Kyvik KO, Kaprio J, Hofman A, Freimer NB, Jarvelin MR, Gyllensten U, Campbell H, Rudan I, Johansson A, Marroni F, Hayward C, Vitart V, Jonasson I, Pattaro C, Wright A, Hastie N, Pichler I, Hicks AA, et al.: Loci influencing lipid levels and coronary heart disease risk in 16 European population cohorts. Nat Genet 2009, 41:47-55

13. Cichon S, Craddock N, Daly M, Faraone SV, Gejman PV, Kelsoe J, Lehner T, Levinson DF, Moran A, Sklar P, Sullivan PF: Genomewide association studies: history, rationale, and prospects for psychiatric disorders. Am J Psychiatry 2009, 166:540-556. 
14. Owen MJ, Williams HJ, O'Donovan MC: Schizophrenia genetics: advancing on two fronts. Curr Opin Genet Dev 2009, 19:266-270.

15. Weiss $L A$, Arking DE, Daly MJ, Chakravarti A: A genome-wide linkage and association scan reveals novel loci for autism. Nature 2009, 461:802-808.

16. Moskvina V, Craddock N, Holmans P, Nikolov I, Pahwa JS, Green E, Owen MJ, O'Donovan MC: Gene-wide analyses of genome-wide association data sets: evidence for multiple common risk alleles for schizophrenia and bipolar disorder and for overlap in genetic risk. Mol Psychiatry 2009, 14:252-260.

17. de Geus EJ: Introducing genetic psychophysiology. Biol Psychol 2002, 61:1-10.

18. De Geus EJ, Boomsma DI: A genetic neuroscience approach to human cognition. Eur Psychol 2001, 6:241-253

19. Gottesman II: Schizophrenia Genesis. New York: WH Freeman; 1991.

20. Nieuwenhuis S, Aston-Jones G, Cohen JD: Decision making, the P3, and the locus coeruleus-norepinephrine system. Psychol Bull 2005, 131:510-532.

21. Nieuwenhuis S, de Geus EJ, Aston-Jones G: The anatomical and functional relationship between the $\mathrm{P} 3$ and autonomic components of the orienting response. Psychophysiology 2010, doi:10.1111/j.1469-8986.2010.01057.x.

22. Harmon-Jones E, Gable PA, Peterson CK: The role of asymmetric frontal cortical activity in emotion-related phenomena: A review and update. Biol Psychol 2009, doi:10.1016/j.biopsycho.2009.08.010.

23. Coan JA, Allen JJ, McKnight PE: A capability model of individual differences in frontal EEG asymmetry. Biol Psychol 2006, 72:198-207.

24. Gray JA: The Neuropsychology of Anxiety. Oxford: Clarendon; 1982.

25. Eysenck HJ, Eysenck MW: Personality and Individual Differences. New York: Plenum; 1985.

26. Coan JA, Allen JJ: Frontal EEG asymmetry as a moderator and mediator of emotion. Biol Psychol 2004, 67:7-49.

27. Davidson RJ: Anterior cerebral asymmetry and the nature of emotion. Brain Cogn 1992, 20:125-151.

28. Turetsky BI, Calkins ME, Light GA, Olincy A, Radant AD, Swerdlow NR: Neurophysiological endophenotypes of schizophrenia: the viability of selected candidate measures. Schizophr Bull 2007, 33:69-94.

29. Perlman G, Johnson W, lacono WG: The heritability of P300 amplitude in 18-year-olds is robust to adolescent alcohol use. Psychophysiology 2009, 46:962-969.

30. Smit DJ, Posthuma D, Boomsma DI, Geus EJ: Heritability of background EEG across the power spectrum. Psychophysiology 2005, 42:691-697.

31. Smit DJ, Boersma M, Van Beijsterveldt CE, Posthuma D, Boomsma DI, Stam CJ, de Geus EJ: Endophenotypes in a dynamically connected brain. Behav Genet 2010, 40:167-177.

32. Zietsch BP, Hansen JL, Hansell NK, Geffen GM, Martin NG, Wright MJ: Common and specific genetic influences on EEG power bands delta, theta, alpha, and beta. Biol Psychol 2007, 75:154-164.

33. Posthuma D, Neale MC, Boomsma DI, de Geus EJ: Are smarter brains running faster? Heritability of alpha peak frequency, IQ, and their interrelation. Behav Genet 2001, 31:567-579
34. Smit CM, Wright MJ, Hansell NK, Geffen GM, Martin NG: Genetic variation of individual alpha frequency (IAF) and alpha power in a large adolescent twin sample. Int J Psychophysiol 2006, 61:235-243.

35. Linkenkaer-Hansen K, Smit DJ, Barkil A, van Beijsterveldt TE, Brussaard AB, Boomsma DI, van Ooyen A, de Geus EJ: Genetic contributions to long-range temporal correlations in ongoing oscillations. J Neurosci 2007, 27:13882-13889.

36. Smit DJ, Posthuma D, Boomsma DI, de Geus EJ: The relation between frontal EEG asymmetry and the risk for anxiety and depression. Biol Psychol 2007, 74:26-33.

37. Hall MH, Schulze K, Rijsdijk F, Kalidindi S, McDonald C, Bramon E, Murray RM, Sham P: Are auditory P300 and duration MMN heritable and putative endophenotypes of psychotic bipolar disorder? A Maudsley Bipolar Twin and Family Study. Psychol Med 2009, 39:1277-1287.

38. Smit DJ, Posthuma D, Boomsma DI, de Geus EJ: Heritability of anterior and posterior visual N1. Int J Psychophysiol 2007, 66:196-204.

39. Anokhin AP, Heath AC, Myers E: Genetics, prefrontal cortex, and cognitive control: a twin study of event-related brain potentials in a response inhibition task. Neurosci Lett 2004, 368:314-318.

40. Anokhin AP, Golosheykin S, Heath AC: Heritability of frontal brain function related to action monitoring. Psychophysiology 2008, 45:524-534.

41. Smit DJ, Posthuma D, Boomsma DI, de Geus EJ: Genetic contribution to the P3 in young and middle-aged adults. Twin Res Hum Genet 2007, 10:335-347

42. Wright MJ, Hansell NK, Geffen GM, Geffen LB, Smith GA, Martin NG: Genetic influence on the variance in P3 amplitude and latency. Behav Genet 2001, 31:555-565.

43. Posthuma D, Mulder EJ, Boomsma DI, de Geus EJ: Genetic analysis of IQ processing speed and stimulus-response incongruency effects. Biol Psychol 2002, 61:157-182.

44. Van't Ent D, Van Soelen IL, Stam KJ, de Geus EJ, Boomsma DI: Genetic influence demonstrated for MEG-recorded somatosensory evoked responses. Psychophysiology 2010, doi:10.1111/j.1469-8986.2010.01012.x.

45. Van't Ent D, Van Soelen IL, Stam CJ, de Geus EJ, Boomsma DI: Strong resemblance in the amplitude of oscillatory brain activity in monozygotic twins is not caused by "trivial" similarities in the composition of the skull. Hum Brain Mapp 2009, 30:2142-2145.

46. Miller G, Holden C: Psychiatry. Proposed revisions to psychiatry's canon unveiled. Science 2010, 327:770-771

47. Anokhin AP, Vedeniapin AB, Heath AC, Korzyukov O, Boutros NN: Genetic and environmental influences on sensory gating of mid-latency auditory evoked responses: a twin study. Schizophr Res 2007, 89:312-319.

doi:10.1186/gm184

Cite this article as: de Geus EJC: From genotype to EEG endophenotype: a route for post-genomic understanding of complex psychiatric disease? Genome Medicine 2010, 2:63. 